Research article

\title{
Expression of cartilage-derived morphogenetic protein in human intervertebral discs and its effect on matrix synthesis in degenerate human nucleus pulposus cells
}

\author{
Christine L Le Maitre ${ }^{1,2}$, Anthony J Freemont ${ }^{2}$ and Judith A Hoyland ${ }^{2}$
}

\author{
1Biomedical Research Centre, Biosciences, Faculty of Health and Wellbeing, Sheffield Hallam University, City Campus, Owen Building, Howard \\ Street, Sheffield, S1 1WB, UK \\ ${ }^{2}$ Tissue Injury and Repair Group, School of Clinical and Laboratory Sciences, Faculty of Medical and Human Sciences, Stopford Building, The \\ University of Manchester, Oxford Road, Manchester, M13 9PT, UK \\ Corresponding author: Judith A Hoyland, judith.hoyland@manchester.ac.uk
}

Received: 26 Mar 2009 Revisions requested: 15 May 2009 Revisions received: 30 Jul 2009 Accepted: 15 Sep 2009 Published: 15 Sep 2009

Arthritis Research \& Therapy 2009, 11:R137 (doi:10.1186/ar2808)

This article is online at: http://arthritis-research.com/content/11/5/R137

(c) 2009 Le Maitre et al.; licensee BioMed Central Ltd.

This is an open access article distributed under the terms of the Creative Commons Attribution License (http://creativecommons.org/licenses/by/2.0), which permits unrestricted use, distribution, and reproduction in any medium, provided the original work is properly cited.

\begin{abstract}
Introduction Loss of intervertebral disc (IVD) matrix and ultimately disc height as a result of 'degeneration' has been implicated as a major cause of low back pain (LBP). The use of anabolic growth factors as therapies to regenerate IVD matrix, hence restoring disc height and thus reversing degenerative disc disease, has been suggested. Cartilage-derived morphogenetic protein (CDMP) is a growth factor which stimulates proteoglycan production in chondrocyte-like cells and thus could be a useful growth factor for LBP therapies. However, little is known about the expression of CDMP or its receptor in human IVD, nor its effects on human disc cells.
\end{abstract}

Methods Using immunohistochemistry we investigated the localisation of CDMP in non-degenerate and degenerate human IVDs. Additionally, we investigated the effect of CDMP on aggrecan and type II collagen gene expression and proteoglycan synthesis in nucleus pulposus (NP) cells derived from degenerate IVDs.

Results We demonstrated that CDMP 1 and 2 were expressed in the non-degenerate and degenerate IVD, particularly in cells of the NP. A small decrease in the number of CDMP 1 and 2 immunopositive cells was seen with degeneration. Treatment of human NP cells, (derived from degenerate IVD), with CDMP showed an increase in aggrecan and type II collagen gene expression and increased production of proteoglycan (GAGs).

Conclusions The data suggests that CDMP may be a useful growth factor to stimulate proteoglycan production in the human degenerate IVD and hence the repair of the extracellular matrix.

\section{Introduction}

Low back pain (LBP) is a major problem in the western world, affecting approximately 11 million people in the UK for at least one week each month [1]. It leads to a considerable loss of working days and has a significant impact on the national health service [2]. Imaging studies indicate a link between degeneration of the intervertebral disc (IVD) and LBP $[3,4]$. However, current conservative and invasive interventions for IVD degeneration, aimed at improving LBP, are only directed towards symptomatic relief. Currently, there are few treat- ments aimed at repairing the degenerate IVD, which if developed could not only relieve symptoms but prevent their reoccurrence through restoration of normal IVD structure and function. Modern advances in therapeutics, particularly cell and tissue engineering, offer potential methods for inhibiting or reversing IVD degeneration that have not previously been possible. However, to ensure success they require a greater level of understanding of the pathobiology of IVD degeneration than is currently available [5].

AF: annulus fibrosus; BMP: bone morphogenetic protein; BMP RII: BMP receptor 2; BSA: bovine serum albumin; CDMP: cartilage derived morphogenetic protein; CM: cell-associated matrix; DMEM: Dulbecco's modified eagle medium; DMMB: dimethylmethylene blue; FGF: fibroblast growth factor; FGF R3: FGF receptor 3; FRM: further removed matrix; GAGs: glycosaminoglycans; GDF: growth differentiation factor; H\&E: haematoxylin and eosin; IAF: inner annulus fibrosus; Ig: immunoglobulin; IGF: insulin-like growth factor; IGF RI: IGF receptor 1; IHC: immunohistochemistry; IVD: intervertebral disc; LBP: low back pain; MMP: matrix metalloproteinase; NP: nucleus pulposus; OA: osteoarthritis; OAF: outer annulus fibrosus; PCR: polymerase chain reaction; TGF: transforming growth factor; TGF RII: TGF receptor 2. 
The IVD is composed of a proteoglycan rich nucleus pulposus (NP), which is constrained by the surrounding annulus fibrosus (AF) and cartilaginous endplates. During IVD degeneration there is a change in cell phenotype resulting in decreased matrix production, particularly proteoglycan synthesis, and an increase in degradation of IVD matrix by locally produced matrix metalloproteinases (MMPs) and ADAMTS (a disintegrin and metalloprotease with thrombospondin motifs) $[6,7]$. The overall loss of normal disc matrix results in decreased weight bearing capacity, leading to the generation of fissures, annular tears and the generation of pain.

Several studies have suggested the use of anabolic growth factors to regenerate the matrix of the IVD and hence restore disc height, thereby reversing degenerative disc disease. Numerous growth factors have been implicated and those that have attracted the most attention include transforming growth factor (TGF), insulin-like growth factor (IGF), bone morphogenetic proteins (BMPs), cartilage derived morphogenetic proteins (CDMPs) and fibroblast growth factor (FGF). All these factors have been investigated in in vitro studies together with some in vivo animal studies, and due to their ability to stimulate the synthesis of matrix components of the IVD, (particularly proteoglycans), have been postulated to be therapeutic agents for the restoration of IVD matrix [8-15]. Our previous study investigating the localisation of these growth factor receptors, demonstrated expression of TGF RII, FGF R3 and IGF RI in the endothelial cells of blood vessels, as well as the native IVD cells. This suggests that the addition of such growth factors may induce blood vessel ingrowth, which could be detrimental in any treatment, because it has been reported that this is also accompanied by nerve ingrowth [16]. In contrast BMP RIl expression was not observed in blood vessels suggesting that growth factors which utilise these receptors (i.e. BMPs and CDMPs) may be preferable agents for the regeneration of disc matrix in disc degeneration [17].

Two growth factors thought to stimulate proteoglycan synthesis in chondrocyte-like cells are CDMP 1 and CDMP 2 also known as BMP 14 and BMP 13 or growth and differentiation factor (GDF) 5 and 6, respectively. The distribution and effects of these growth factors have been studied in human articular cartilage in vitro $[18,19]$. In addition, the effect of these growth factors in animal models of IVD degeneration has also been studied but their expression in or effect on human IVD cells is still not fully understood [9,20-22].

Here we investigated the expression and localisation of CDMP 1 and 2 in non-degenerate and degenerate human IVDs to ascertain how their expression alters with IVD degeneration. We have previously investigated the expression of the CDMP receptor and here we relate the expression and distribution of CDMP to that seen previously for the receptor BMP RII [17]. Furthermore, the effect of CDMP 1 on cell proliferation, aggrecan and collagen type II gene expression and proteoglycan production in human NP cells derived from degenerate discs was also investigated.

\section{Materials and methods Tissue samples}

Human IVD tissue was obtained either during surgery or post mortem examination with informed consent of the patient or relatives. Local research ethics committee approval was given for this work by the following Local Research Ethics Committees: Salford and Trafford, Bury and Rochdale, Central Manchester and Her Majesty's coroner.

\section{Post mortem tissue}

Discs recovered from patients within 18 hours of death consisted of full thickness wedges of IVD of $120^{\circ}$ arc removed anteriorly. This allowed well-orientated blocks of tissue incorporating $\mathrm{AF}$ and NP to be cut for histological study. Patients with a history of sciatica sufficient to warrant seeking medical opinion, were excluded from the study.

\section{Surgical tissue}

Patients were selected on the basis of IVD degeneration diagnosed by magnetic resonance imaging and progression to anterior resection either for spinal fusion or disc replacement surgery for chronic LBP. Patients experiencing classical sciatica were excluded from the study. Some patients underwent fusion at more than one disc level because of spinal instability. Occasionally the specimens retrieved from multilevel fusion included discs with low ( 0 to 3 [see below for details of the scoring system]) histological scores (i.e. morphologically normal) at one level (Table 1). Wedges of disc tissue were removed in a manner similar to that described for cadavers.

\section{General procedure for tissue specimens}

A block of tissue, incorporating AF and NP in continuity was fixed in 10\% neutral buffered formalin, decalcified in EDTA and processed into paraffin wax. Sections were taken for H\&E staining to score the degree of morphological degeneration according to previously published criteria [23]. A score of 0 to 3 represents a histologically normal (non-degenerate) disc, 4 to 8 indicates evidence of intermediate degeneration and 9 to 12 indicated severe degeneration. From this histological scoring, 30 discs were selected to represent a range of scores from non-degenerate (grades 1 to 3 ) up to the most severe level of histological degeneration (grade 12).

\section{Localisation of CDMP 1 and 2}

Immunohistochemistry (IHC) was used to localise the growth factors CDMP 1 and 2 within the 30 disc samples (Table 1). The IHC protocol followed was as previously published [6]. Briefly, $4 \mu \mathrm{m}$ paraffin sections were dewaxed, rehydrated and endogenous peroxidase blocked using hydrogen peroxide. After washing in distilled water sections were treated with chymotrypsin enzyme antigen retrieval system $(0.01 \% \mathrm{w} / \mathrm{v}$ chymotrypsin (Sigma, Gillingham, Dorset, UK) for 20 minutes at 
Patient details and grades of tissues used for immunohistochemistry analysis

\begin{tabular}{|c|c|c|c|c|}
\hline Source & Age (years) & Clinical diagnosis & Disc level & Histological grade \\
\hline Surgical & 15 & Normal & $\mathrm{L} 4 / 5$ & 0 \\
\hline Surgical & 41 & Normal & L5/S1 & 0 \\
\hline Surgical & 44 & Normal & L4/5 & 0 \\
\hline Surgical & 41 & Normal & $\mathrm{L} 4 / 5$ & 0 \\
\hline Surgical & 41 & Normal & L5/S1 & 0 \\
\hline Surgical & 33 & Disc degeneration & $\mathrm{L} 4 / 5$ & 1 \\
\hline Surgical & 20 & Disc degeneration & L5/S1 & 2 \\
\hline Surgical & 44 & Disc degeneration & L4/5 & 2 \\
\hline Surgical & 47 & Disc degeneration & $\llcorner 4 / 5$ & 2 \\
\hline Surgical & 40 & Disc degeneration & $\llcorner 4 / 5$ & 2 \\
\hline Surgical & 39 & Disc degeneration & L5/S1 & 5 \\
\hline Surgical & 25 & Disc degeneration & $\mathrm{L} 4 / 5$ & 5 \\
\hline Surgical & 40 & Disc degeneration & $\mathrm{L} 4 / 5$ & 6 \\
\hline Surgical & 25 & Disc degeneration & L5/S1 & 6 \\
\hline Post mortem & 47 & No data & $\llcorner 4 / 5$ & 6 \\
\hline Surgical & 43 & Disc degeneration & $\mathrm{L} 4 / 5$ & 7 \\
\hline Surgical & 37 & Disc degeneration & $\llcorner 4 / 5$ & 7 \\
\hline Surgical & 55 & Disc degeneration & L5/S1 & 7 \\
\hline Post mortem & Not Known & No Data & L4/5 & 7 \\
\hline Surgical & 44 & Disc degeneration & L5/S1 & 8 \\
\hline Surgical & 33 & Disc degeneration & $\llcorner 4 / 5$ & 9 \\
\hline Surgical & 46 & Disc degeneration & $\llcorner 4 / 5$ & 9 \\
\hline Surgical & 37 & Disc degeneration & $\llcorner 4 / 5$ & 9 \\
\hline Surgical & 56 & Disc degeneration & $\llcorner 4 / 5$ & 9 \\
\hline Surgical & 33 & Disc degeneration & Unknown & 9 \\
\hline Surgical & 68 & Disc degeneration & L5/S1 & 10 \\
\hline Surgical & 32 & Disc degeneration & $\llcorner 4 / 5$ & 10 \\
\hline Surgical & 45 & Disc degeneration & L5/S1 & 10 \\
\hline Surgical & 52 & Disc degeneration & Unknown & 10 \\
\hline Surgical & 45 & Disc degeneration & $\mathrm{L} 4 / 5$ & 11 \\
\hline
\end{tabular}

$\left.37^{\circ} \mathrm{C}\right)$. Following washing, non-specific binding sites were blocked at room temperature for 45 minutes in $25 \% \mathrm{w} / \mathrm{v}$ donkey serum in 1\% w/v BSA (Sigma, Gillingham, Dorset, UK). Sections were incubated overnight at $4^{\circ} \mathrm{C}$ with goat polyclonal primary antibodies against human CDMP 1 (1:200 dilution, SantaCruz biotechnology, SantaCruz, California, USA) and CDMP 2 (1:500 dilution, SantaCruz biotechnology, SantaCruz, California, USA). Negative controls in which goat immunoglobulin (Ig) Gs (Dako, Ely, Cambridgeshire, UK) replaced the primary antibody (at an equal protein concentration) were used.

After washing, sections were incubated in a 1:300 dilution of biotinylated donkey anti-goat antiserum (SantaCruz biotechnology, SantaCruz, California, USA) for 30 minutes at room temperature. Disclosure of secondary antibody binding was by the streptavidin-biotin complex (Dako, Ely, Cambridgeshire, UK) technique with 3,3'-diaminobenzidine tetrahydrochloride 
solution (Sigma, Gillingham, Dorset, UK). Sections were counterstained with Mayers Haematoxylin (Raymond A Lamb, Eastbourne, East Sussex, UK), dehydrated and mounted in XAM (BDH, Poole, UK).

Image analysis

All slides were visualised using Leica RMDB research microscope and images captured using a digital camera and Bioquant Nova image analysis system (BIOQUANT Image Analysis Corporation, Nashville TN, USA). Each section was divided into three areas for analysis: the NP, inner annulus fibrosus (IAF) and outer annulus fibrosus (OAF) and analysed separately. Within each area 200 cells were counted and the number of immunopositive cells expressed as a proportion of this. Averages and standard deviations were calculated for disc sections grouped with the scores 0 to 3,4 to 8 and 9 to 12. Data was then presented as means \pm standard errors.

\section{Statistical analysis}

Data was non-parametric and thus Kruskal Wallis with all pairwise comparisons post hoc test Conover-Inman was used to compare the numbers of immunopositive cells in degenerate groups (4 to 8 , and 9 to 12 ) to non-degenerate discs (scores 0 to 3). These tests were performed for each area of the disc analysed (i.e. NP, IAF and OAF). In addition Wilcoxon paired samples tests were used to compare proportions of immunopositive cells in the different areas of the discs (i.e. NP v/s IAF, $\mathrm{NP} v / \mathrm{s} \mathrm{OAF}$ and IAF v/s OAF). This analysis was performed using all disc sections regardless of level of degeneration.

\section{Effect of CDMP on human NP samples in alginate culture} Isolation of disc cells

Samples of degenerate IVD tissue were obtained from three patients undergoing surgery for disc replacement for the treatment of chronic LBP (75-year-old male (Grade 7); 37-year-old female (Grade 9); and 35-year-old female (Grade 10)). NP tissue was separated and finely minced and digested with $2 \mathrm{U} /$ $\mathrm{ml}$ protease (Sigma, Gillingham, Dorset, UK) in DMEM + F12 media for 30 minutes at $37^{\circ} \mathrm{C}$ and washed twice in DMEM + $\mathrm{F} 12$. NP cells were isolated in $0.4 \mathrm{mg} / \mathrm{ml}$ collagenase type 1 (Gibco, Paisley, UK) for four hours at $37^{\circ} \mathrm{C}$.

\section{Alginate culture}

It is well recognised that cells derived from IVDs change their morphology and phenotype in monolayer culture becoming similar to fibroblasts. However, culturing the cells in systems such as alginate can restore the IVD cell phenotype [24]. We therefore used cells in alginate beads to investigate the effects of CDMP on cell proliferation, gene expression for aggrecan and type II collagen and proteoglycan production. Following isolation, cells were expanded in monolayer culture for two weeks prior to trypsinisation and resuspension in $1.2 \% \mathrm{w} / \mathrm{v}$ medium-viscosity sodium alginate (Sigma, Gillingham, Dorset, UK) in $0.15 \mathrm{M} \mathrm{NaCl}$ at a density of $4 \times 10^{6}$ cells $/ \mathrm{ml}$ and alginate beads polymerised via extrusion through a 19-gauge nee- dle into $200 \mathrm{mM} \mathrm{CaCl}$. Following washes in $0.15 \mathrm{M} \mathrm{NaCl}$ beads were transferred to culture plates and $2 \mathrm{ml}$ of complete culture medium was then added to each well and cultures maintained at $37^{\circ} \mathrm{C}$ in a humidified atmosphere containing $5 \%$ $\mathrm{CO}_{2}$.

\section{Treatment of cells with CDMP}

Following one week in this culture system, cells were treated for two weeks with either $0 \mathrm{ng} / \mathrm{ml}$ or $10 \mathrm{ng} / \mathrm{ml}$ CDMP 1 (Autogen Bioclear, Wiltshire, UK); all treatments were performed six times. Media was changed and CDMP replaced every 48 hours. Conditioned media at each media change was frozen at $-20^{\circ} \mathrm{C}$ for further analysis.

\section{Papain digest and DMMB assay}

Following treatments, triplicate samples (six beads per sample) were used for quantification of DNA and glycosaminoglycans (GAG) content using the pico green assay (Invitrogen, Paisley, UK) and the dimethylmethylene blue (DMMB) assay.

The beads were solubilised by incubation for 20 minutes at $4^{\circ} \mathrm{C}$ in dissolving buffer containing $55 \mathrm{mM}$ sodium citrate, 30 $\mathrm{mM} \mathrm{Na}{ }_{2}$ EDTA and $0.15 \mathrm{M} \mathrm{NaCl}, \mathrm{pH}$ 6.8. The resulting suspension was subjected to mild centrifugation $(100 \mathrm{~g}$ for $10 \mathrm{~min}$ utes) to separate the cells and their associated matrix in the pellet (cell-associated matrix (CM) compartment) from molecules derived from the matrix further removed from the cell surface in the supernatant (further removed matrix (FRM) compartment) as described previously [25]. The fractions were separated into fresh tubes and digested overnight at $60^{\circ} \mathrm{C}$ in $500 \mu \mathrm{l} 20 \mathrm{mM}$ sodium phosphate buffer ( $\mathrm{pH}$ 6.8) containing $1 \mathrm{mM}$ EDTA, $2 \mathrm{mM}$ dithiothereitol and 100 units of papain (Sigma, Gillingham, Dorset, UK). DMMB assay was then performed using $25 \mu \mathrm{l}$ of shark chondrotin sulphate (Sigma, Gillingham, Dorset, UK) standards $(62.5 \mu \mathrm{g} / \mathrm{ml}, 31.25$ $\mu \mathrm{g} / \mathrm{ml}, 15.625 \mu \mathrm{g} / \mathrm{ml}, 7.81 \mu \mathrm{g} / \mathrm{ml}, 3.9 \mu \mathrm{g} / \mathrm{ml}$ and $0 \mu \mathrm{g} / \mathrm{ml}), 5 \mu \mathrm{l}$ papain digested CM samples or $5 \mu$ papain digested FRM samples or $50 \mu \mathrm{l}$ conditioned media collected at each media change. Each sample was applied in duplicate in separate wells of a 96-well plate and $200 \mu \mathrm{l}$ of DMMB colour regent (as described previously [26]) was added to each well. Following mixing, absorbance at $A_{525 \mathrm{~nm}}$ was read immediately using a Titertex Multiscan ${ }^{\circledR}$ MC (Thermo Fisher, Paisley, UK). The concentration of GAGs present within each sample and total GAGs accumulated in the media over the two weeks was calculated. DNA from papain digests of cell-associated fractions were assayed along with calf thymus DNA standards using the Pico Green DNA quantification kit as per manufactures' instructions. GAG concentration was then normalised to DNA content per bead and means and standard errors calculated. In addition DNA content per bead was calculated as an indication of cell proliferation. 
RNA extraction, and reverse transcription

Following treatments, triplicate alginate bead samples (six beads per sample) were used for analysis of aggrecan and type II collagen gene expression. RNA was extracted using TRIzol ${ }^{\circledR}$ I reagent (Gibco, Paisley, UK). Prior to TRIzol ${ }^{\circledR}$ extraction, alginate constructs were washed in $0.15 \mathrm{M} \mathrm{NaCl}$ and dissolved in dissolving buffer $(55 \mathrm{mM}$ sodium citrate, $30 \mathrm{mM}$ EDTA, $0.15 \mathrm{M} \mathrm{NaCl} ; \mathrm{pH} 6$ ) at $37^{\circ} \mathrm{C}$ for 15 minutes and then digested in $0.06 \% \mathrm{w} / \mathrm{v}$ collagenase type I (Gibco, Paisley, UK) for 30 minutes to allow digestion of matrix. Following RNA extraction, reverse transcription was performed using avian myeloblastosis virus reverse transcriptase (Roche, East Sussex, UK).

\section{Real-time PCR}

Real-time PCR was used to investigate the effects of CDMP on aggrecan (FP: 3'CCG TGT GTC CAA GGA GAA GG 5'; probe: 3'FAM- CTG ATA GGC ACT GTT GAC - MGB 5'; RP: 3' GGG TAG TTG GGC AGT GAG AC 5') (Accession numbers: [GenBank:NM_001135.2] (variant 1) and [GenBank:NM 013227.2] (variant 2) primers recognise both variants; Applied Biosystems, Warrington, UK) and type II alpha 1 collagen (FP: 3' ATG GAG ACT GGC GAG ACT TG 5'; probe: 3' FAM - CCC AAT CCA GCA AAC G - MGB 5'; RP: GCT GCT CCA CCA GTT CTT 5') (Accession numbers: [GenBank:NM 001844.4] (variant 1) and [GenBank:NM 033150.2] (variant 2) primers recognise both variants; Applied Biosystems, Warrington, UK) gene expression using $18 \mathrm{~s}$ as the housekeeping gene (PDAR: Applied Biosys- tems, Warrington, UK) and genomic DNA standard curves to generate copy number per $100 \mathrm{ng}$ cDNA as described previously [27].

\section{Statistical analysis}

Mann Whitney $U$ tests were used to compare untreated and CDMP-treated samples to investigate significant differences in DNA content, GAG content and release into media and aggrecan and type II collagen gene expression.

\section{Results}

Immunohistochemical localisation of CDMP 1 and CDMP 2

Immunopositive staining for both CDMP 1 and CDMP 2 was restricted to the cytoplasm of native disc cells in both nondegenerate and degenerate discs and there was no statistical significance between non-degenerate and degenerate discs $(P>0.05$; Table 2$)$. Staining was particularly prominent in the cytoplasm of the chondrocyte-like cells of the NP and IAF, with both single cells and those in clusters showing immunopositivity (Figures 1 and 2). CDMP 1 immunopositivity was observed in a higher proportion of cells in both non-degenerate and degenerate discs than CDMP $2(P<0.05)$. A greater proportion of cells were immunopositive for CDMP 1 and CDMP 2 in the NP than the IAF $(P<0.05)$, and the proportion of immunopositive cells in the OAF was always lower than that seen in the NP and IAF (all targets $P<0.05$ ). No immunopositivity was observed in the matrix of the IVD or in the endothelial cells of

Figure 1

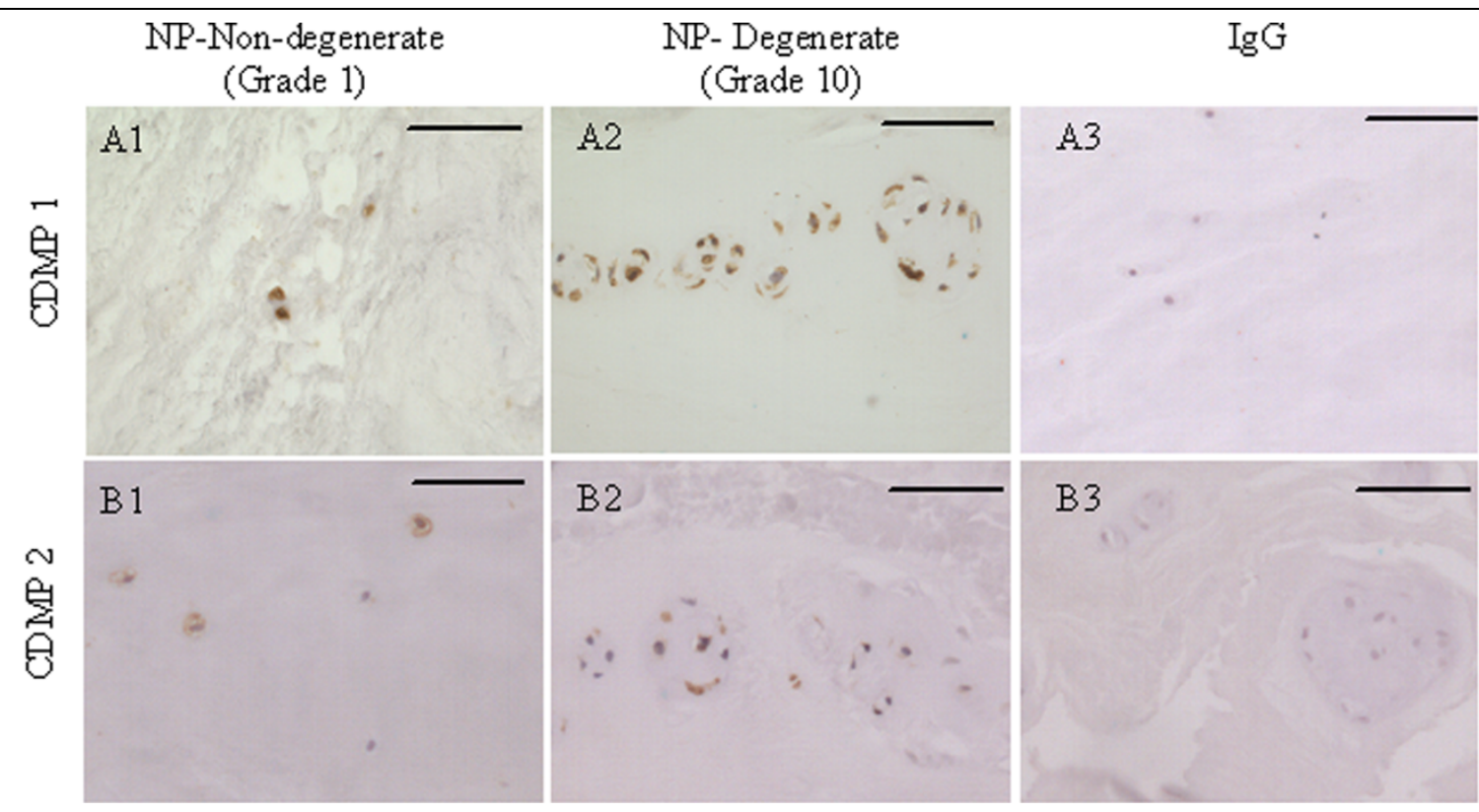

Examples of immunohistochemical staining for CDMPs in human intervertebral disc. (row A) Cartilage derived morphogenetic protein (CDMP 1) and (row B) CDMP 2. Images are of nucleus pulposus of grade 1 non-degenerate discs (column 1), the nucleus pulposus of grade 10 degenerate discs (column 2) and IgG controls for each antibody. Bars $=570 \mu \mathrm{m}$. 
Figure 2

(a) CDMP 1 Immunopositivity In human IVD

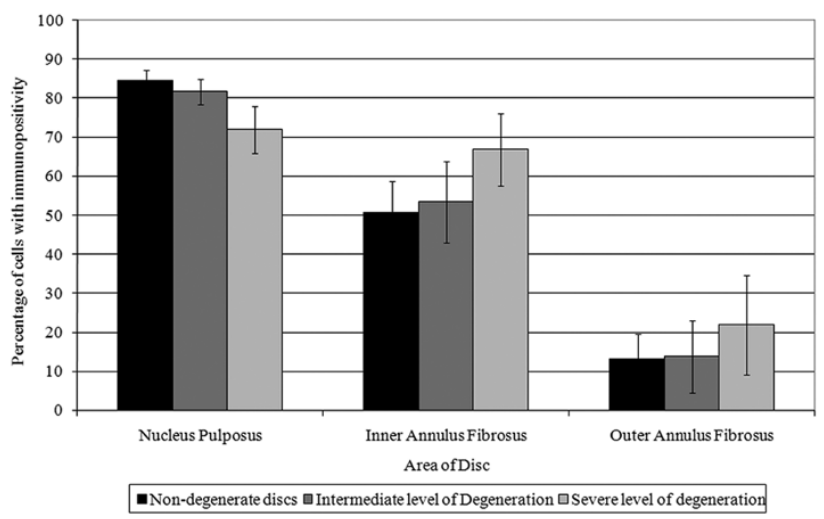

(b) CDMP 2 Immunopositivity in human IVD

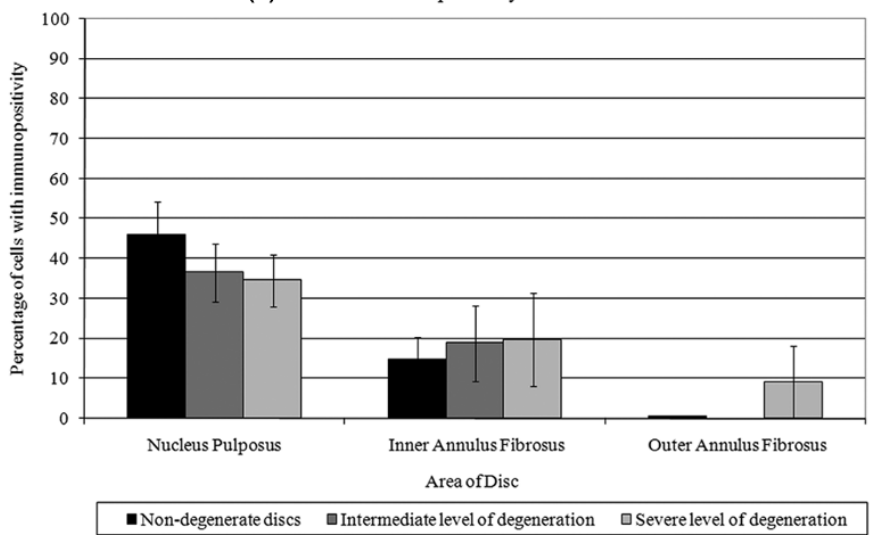

Assessment of immunopositive staining for CDMP 1 and 2 in human intervertebral discs. Percentage of cells with immunopositivity for (a) cartilage derived morphogenetic protein (CDMP) 1, (b) CDMP 2, according to location in the disc and grade of intervertebral disc degeneration ( $\mathrm{n}=30$ ). Data are presented as means \pm standard error. ${ }^{*} P<0.05$ compared with non-degenerate discs.

the blood vessels for either CDMP 1 or $2 . \lg$ G controls were negative (Figure 1).

\section{Immunohistochemical staining for BMP RII}

We have previously shown BMP RII immunopositive staining in the human IVD with a greater number of immunopositive cells within the NP than the IAF and OAF $(P<0.05)$. Furthermore, in IVDs graded as intermediate degeneration there was an increase in the proportion of immunopositive cells, which was significant in the NP $(P<0.05)$ [17]

\section{Effect of CDMP 1 on proliferation of human NP cells derived from degenerate discs}

To determine the effect of CDMP 1 on cellular proliferation DNA content per alginate bead was calculated following two weeks of treatment with CDMP. An increase in DNA content (28\% increase in CDMP-treated cells v/s untreated cells) was observed in the alginate bead cultures treated with CDMP but this did not reach significance $(P=0.35$; Figure 3$)$.
Effect of CDMP 1 on GAG production of human NP cells derived from degenerate discs

A significant increase in overall GAG production (i.e. within the $\mathrm{CM}$, FRM and media together) was observed in NP cells derived from degenerate discs treated with $10 \mathrm{ng} / \mathrm{ml}$ CDMP 1 for two weeks compared with untreated NP cells $(P<0.05)$. An increase in GAG content of CM in CDMP-treated cultures was observed but this did not reach significance $(P=0.43)$. However, the GAG content within the FRM was significantly increased following CDMP 1 treatment for two weeks $(P<$ 0.05). No difference was observed in the GAG released into the media during the two weeks treatment with CDMP from untreated alginate bead cultures of NP cells derived from degenerate discs $(P=0.24$; Figure 4$)$.

Table 2

Analysis of immunohistochemical data: $\boldsymbol{P}$ values for analysis of CDMP1 and 2 expression in different areas of disc in nondegenerate $\mathrm{v} / \mathrm{s}$ degenerate discs

\begin{tabular}{lll}
\hline IVD area analysed for CDMP expression & Intermediate degeneration $(\boldsymbol{P})$ & Severe degeneration $(\boldsymbol{P})$ \\
\hline CDMP 1 expression in NP Non-degenerate v/s degenerate & 0.302 & 0.106 \\
CDMP 1 expression in IAF Non-degenerate v/s degenerate & 0.336 & 0.112 \\
CDMP 1 expression in OAF Non-degenerate v/s degenerate & 0.461 & 0.362 \\
CDMP 2 expression in NP Non-degenerate v/s degenerate & 0.241 & 0.124 \\
CDMP 2 expression in IAF Non-degenerate v/s degenerate & 0.479 & 0.521 \\
CDMP 2 expression in OAF Non-degenerate v/s degenerate & 0.679 & 0.465
\end{tabular}

$\mathrm{CDMP}=$ cartilage derived morphogenetic protein; IAF $=$ inner annulus fibrosus; IVD $=$ intervertebral disc; $N P=$ nucleus pulposus; $\mathrm{OAF}=$ outer annulus fibrosus. 
DNA content of alginate beads containing NP cells derived from degenerate discs treated with CDMP for 2 wks

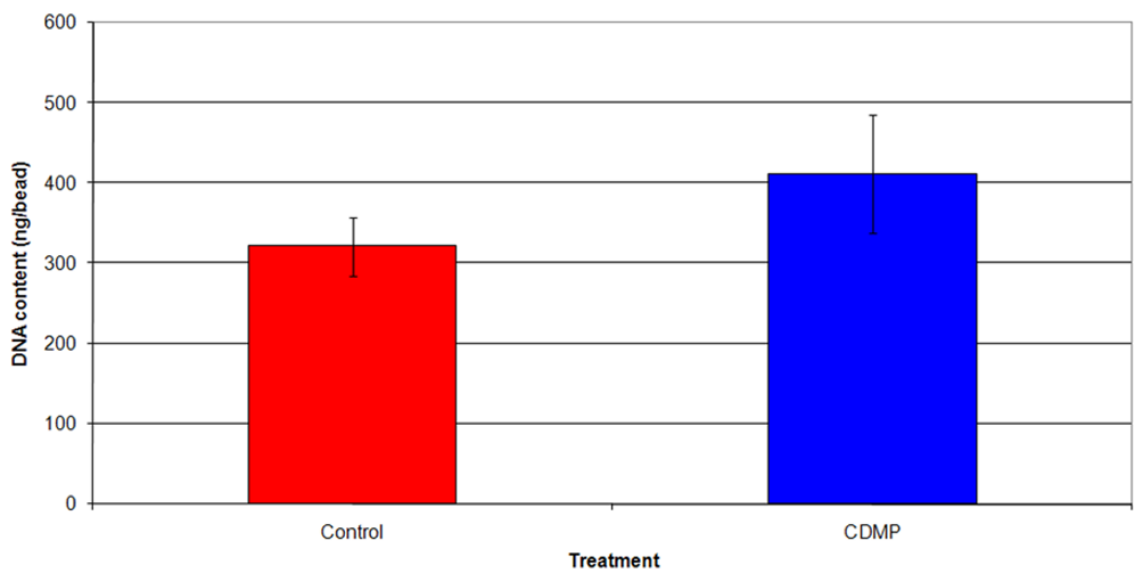

Effect of CDMP treatment on DNA content of alginate beads containing NP cells derived from degenerate discs treated with CDMP for two weeks. Data are presented as means \pm standard error. $C D M P=$ cartilage derived morphogenetic protein; NP $=$ nucleus pulposus.

\section{Effect of CDMP 1 on gene expression for aggrecan and collagen type II in human NP cells derived from degenerate discs}

A significant increase in both aggrecan (3831-fold increase) and collagen type II (1660-fold increase) gene expression was observed in NP cells derived from degenerate discs cultured in alginate beads and treated with $10 \mathrm{ng} / \mathrm{ml}$ CDMP 1 for two weeks $(P<0.05$; Figure 5).

\section{Discussion}

A major cause of LBP is degeneration of the IVD, of which proteoglycan loss is a key feature and has been linked to loss in disc height, de-stabilisation of the motion segment and the ingrowth of blood vessels and nerves resulting in generation of pain $[28,29]$. Thus a potential therapeutic approach to repair the degenerate disc would be the stimulation of normal disc matrix production particularly increased synthesis of proteoglycans. A number of growth factors have been suggested as possible therapeutic agents. However, our previous study suggested that the addition of growth factors which bound to TGF RII, FGF R3 and IGF RI may also induce unwanted blood vessel ingrowth [17]. However, we demonstrated that growth factors, such as CDMP 1 and 2, which elicit their response via BMP RII, should not induce blood vessel ingrowth.

Here we demonstrate the synthesis and localisation of CDMP 1 and CDMP 2 within human IVDs. Although a small decrease in the proportion of cells within the NP staining for CDMP 1

Figure 4

GAG content of NP cells extracted from degenerate discs treated with CDMP for $2 w k s$ in alginate

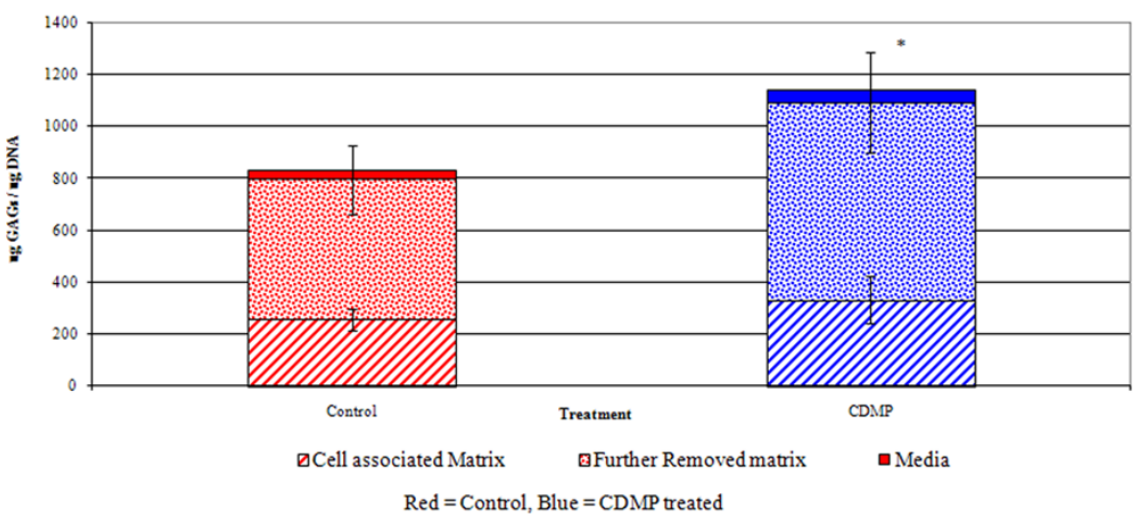

Effect of CDMP treatment on GAG content of NP cells derived from degenerate discs. Data are presented as GAG content of the cell associated matrix, further removed matrix and GAG released into the media per ug DNA (means \pm standard error. ${ }^{\star} P<0.05$ compared with untreated controls). $\mathrm{CDMP}=$ cartilage derived morphogenetic protein; $\mathrm{GAG}=$ glycosaminoglycan; NP = nucleus pulposus. 


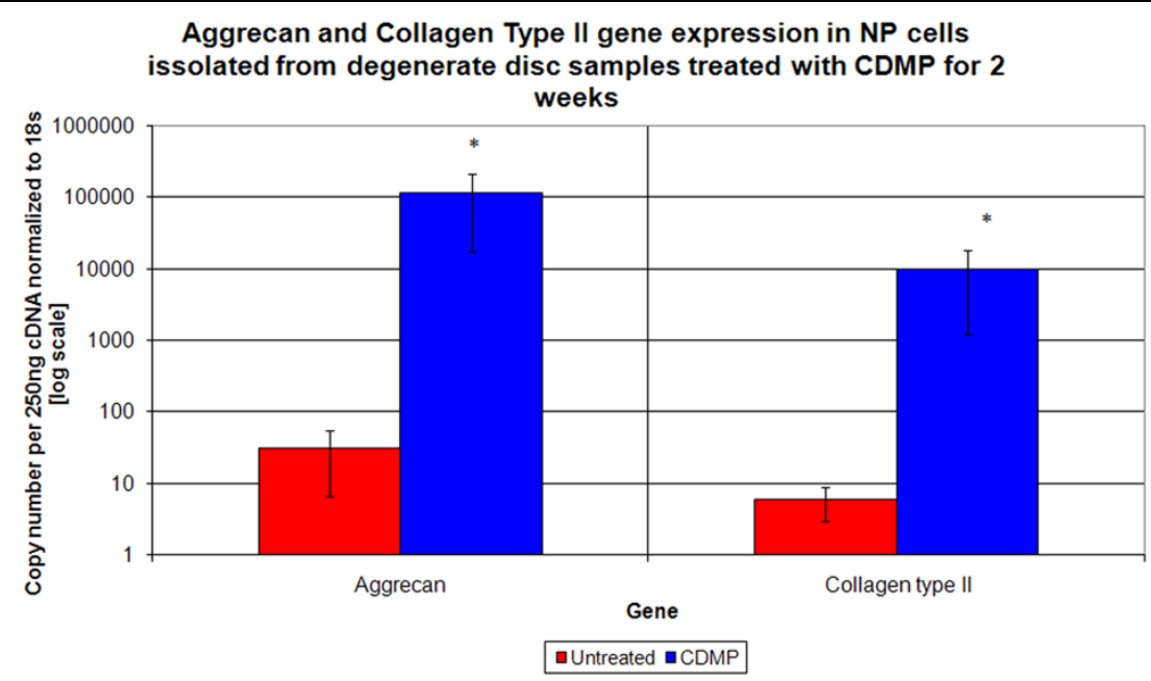

Effect of CDMP treatment on aggrecan and type II collagen gene expression in NP cells derived from degenerate discs treated with CDMP for two weeks. Absolute quantification of copy number per $250 \mathrm{ng}$ cDNA normalized to the housekeeping gene $18 \mathrm{~s}$. Data are presented as means \pm standard error. ${ }^{*} P<0.05$ compared with untreated controls. $\mathrm{CDMP}=$ cartilage derived morphogenetic protein; $\mathrm{NP}=$ nucleus pulposus.

and CDMP 2 was observed during degeneration this was not significant. Similarly Bobacz and colleagues demonstrated that both CDMP 1 and CDMP 2 were expressed in normal and osteoarthritic (OA) articular cartilage with no change seen during $O A$ [18]. This suggests that the pathogenesis of disc degeneration or OA is not associated with a reduced expression of these growth factors.

CDMP has been shown to result in increased proteoglycan production in human mesenchymal stem cells [30], a chondrocyte cell line [31], and in human articular chondrocytes $[18,19]$. Recently, a small number of studies have also demonstrated proteoglycan stimulation in bovine, rabbit and mouse disc cells $[21,22]$. However, to date, no studies have demonstrated an increase in proteoglycan production in degenerate human IVD cells following CDMP treatment. Here we investigated the effect of CDMP 1 on human NP cells cultured in an alginate bead system. Importantly an alginate bead culture system was used as this maintains the in vivo phenotype of IVD cells, which is lost in monolayer culture [25,32]. Our results demonstrate that cells derived from degenerate human discs can also respond to CDMP with an increase in GAG production, although our study only used three patient samples. These results confirm those derived from animal disc cells where CDMP resulted in significant increases in GAG production $[21,22]$. The accumulation of GAG within alginate beads was investigated within the compartments: $\mathrm{CM}$ and FRM, together with GAG released into media. The majority of the GAG produced by the degenerate NP cells was found in the FRM, and this was the area which showed a significant increase in GAG accumulation following treatment with CDMP 1. The CM is thought to represent the highly structured compartment encircling each cell and corresponds to the combined pericellular and territorial matrix pools which surround each cell in vivo $[25,33,34]$. In contrast the more loosely organised compartment known as the FRM, accounting for approximately $95 \%$ of the total volume of matrix, is thought to represent the interterritorial matrix compartment in vivo $[25,34]$. As this area is thought to account for the majority of the matrix in vivo the fact that more GAGs were found in this area of matrix following stimulation with CDMP is promising for future therapeutic approaches.

The current study also showed that CDMP1 induced dramatic increases in the gene expression for the matrix molecules aggrecan and collagen type II within degenerate human NP cells, as has been reported in mouse IVD cells [22]. During disc degeneration the production of both aggrecan and collagen type II is decreased [23,35] leading to reduced hydration and ability to withstand load. Thus, if a growth factor could be applied which can successfully stimulate the synthesis of these important matrix molecules this would be of benefit for regenerating the degenerate disc.

Previous studies investigating the effect of CDMP1 on rabbit disc cells in monolayer [9] and mouse [22] and bovine disc cells in alginate [21] have shown significant increases in cell proliferation. Here we showed a small increase in proliferation of human disc cells in alginate culture following treatment with CDMP1 for two weeks, although, possibly due to the small sample size, this did not reach significance. Increases in proliferation could be of benefit in a therapeutic approach as a mechanism to replace some of the cells lost through apoptosis and senescence which are common features during disc degeneration $[27,36]$. 
Importantly, this study, together with previous animal studies, suggests CDMP could be a useful therapeutic agent in the regeneration of the degenerate IVD and provides supporting evidence for the clinical use of CDMP in human IVD degeneration. Indeed a phase I/ll clinical trail has just started investigating the efficacy and safety of recombinant GDF 5 (CDMP 1) injection into the IVD for degenerative disc disease [37]. However, it must be noted that any proposed therapy may have to target a number of other problems that are associated with disc degeneration. Combinations of factors may be needed in order to promote matrix synthesis and inhibit the increased catabolism seen within the degenerate disc $[38,39]$. Furthermore, it has been shown that the nutrient supply diminishes with degeneration, which may also limit disc cell self-renewal and function [40]. Thus, potential therapeutic growth factors may have to be combined with therapies aimed at restoring disc nutrition or targeted at those patients in which the cartilaginous endplates (through which nutrients are received) are unaffected, that is not calcified, or sclerotic [40].

\section{Conclusions}

Our data demonstrates that CDMP 1 and 2 protein is expressed by both non-degenerate and degenerate discs together with its receptor (BMP RII), suggesting CDMP is involved in the normal matrix homeostasis with the human IVD. Importantly we have demonstrated, for the first time, that human disc cells derived from degenerate discs retain their ability to respond to CDMP and that such treatment leads to an increase in aggrecan and collagen type II gene expression and increased accumulation of GAGs. Together this data suggests that CDMP is an important anabolic growth factor in the IVD and could be a suitable therapy to aid in IVD repair/regeneration, via stimulation of matrix synthesis.

\section{Competing interests}

The authors declare that they have no competing interests.

\section{Authors' contributions}

CLM helped conceive the study, participated in its design, performed the majority of the laboratory work and all the analysis and co-wrote the manuscript. AJF participated in interpretation of data and contributed to the preparation of the final manuscript. JAH conceived the study, secured funding, contributed to its design and co-ordination, participated in interpretation of data and contributed to the preparation of the final manuscript. All authors read and approved the final manuscript.

\section{Acknowledgements}

The authors wish to acknowledge the support of the joint Research Councils (MRC, BBSRC, EPSRC) UK Centre for Tissue Engineering (34/TIE 13617). The work was undertaken in the Human Tissue Profiling Laboratories of the School of Clinical and Laboratory Sciences that receive core support from the ARC (ICAC grant F0551).

\section{References}

1. Borenstein DG: Epidemiology, etiology, diagnostic evaluation, and treatment of low back pain. Curr Opin Rheumatol 2001, 13:128-134.

2. Maniadakis N, Gray A: The economic burden of back pain in the UK. Pain 2000, 84:95-103.

3. Peterson CK, Bolton JE, Wood AR: A cross-sectional study correlating lumbar spine degeneration with disability and pain. Spine 2000, 25:218-223.

4. Luoma K, Riihimaki H, Luukkonen R, Raininko R, Viikari-Juntura E, Lamminen $A$ : Low back pain in relation to lumbar disc degeneration. Spine 2000, 25:487-492.

5. Freemont AJ, Watkins A, Le Maitre C, Jeziorska M, Hoyland JA: Current understanding of cellular and molecular events in intervertebral disc degeneration: implications for therapy. J Pathol 2002, 196:374-379.

6. Le Maitre CL, Freemont AJ, Hoyland JA: Localization of degradative enzymes and their inhibitors in the degenerate human intervertebral disc. J Pathol 2004, 204:47-54.

7. Le Maitre $\mathrm{CL}$, Freemont $\mathrm{A}$, Hoyland J: Human disc degeneration is associated with increased MMP 7 expression. Biotech Histochem 2006, 81:125-131.

8. Osada R, Ohshima H, Ishihara H, Yudoh K, Sakai K, Matsui H, Tsuji $\mathrm{H}$ : Autocrine/paracrine mechanism of insulin-like growth factor-1 secretion, and the effect of insulin-like growth factor-1 on proteoglycan synthesis in bovine intervertebral discs. J Orthop Res 1996, 14:690-699.

9. Wang H, Kroeber M, Hanke M, Ries R, Schmid C, Poller W, Richter W: Release of active and depot GDF-5 after adenovirusmediated overexpression stimulates rabbit and human intervertebral disc cells. J Mol Med 2004, 82:126-134.

10. Li X, Leo BM, Beck G, Balian G, Anderson GD: Collagen and proteoglycan abnormalities in the GDF-5-deficient mice and molecular changes when treating disk cells with recombinant growth factor. Spine 2004, 29:2229-2234.

11. Thompson JP, Oegema TR Jr, Bradford DS: Stimulation of mature canine intervertebral disc by growth factors. Spine 1991, 16:253-260.

12. Li J, Yoon ST, Hutton WC: Effect of bone morphogenetic protein-2 (BMP-2) on matrix production, other BMPs, and BMP receptors in rat intervertebral disc cells. J Spinal Disord Tech 2004, 17:423-428.

13. Masuda K, An HS: Growth factors and the intervertebral disc. Spine J 2004, 4:330S-340S.

14. Masuda K, Oegema TR Jr, An HS: Growth factors and treatment of intervertebral disc degeneration. Spine 2004, 29:2757-2769.

15. Yoon ST, Park JS, Kim KS, Li J, Attallah-Wasif ES, Hutton WC, Boden SD: ISSLS prize winner: LMP-1 upregulates intervertebral disc cell production of proteoglycans and BMPs in vitro and in vivo. Spine 2004, 29:2603-2611.

16. Freemont AJ, Hoyland JA, Baird P, Byers RJ: Expression of NGF $\beta$ in the vasculature of the diseased intervertebral disc. J Pathol 1999, 189:A68.

17. Le Maitre CL, Richardson SM, Baird P, Freemont AJ, Hoyland JA: Expression of receptors for putative anabolic growth factors in human intervertebral disc: implications for repair and regeneration of the disc. J Pathol 2005, 207:445-452.

18. Bobacz K, Gruber R, Soleiman A, Graninger WB, Luyten FP, Erlacher L: Cartilage-derived morphogenetic protein-1 and $\mathbf{- 2}$ are endogenously expressed in healthy and osteoarthritic human articular chondrocytes and stimulate matrix synthesis. Osteoarthritis Cartilage 2002, 10:394-401.

19. Erlacher L, Ng CK, Ullrich R, Krieger S, Luyten FP: Presence of cartilage-derived morphogenetic proteins in articular cartilage and enhancement of matrix replacement in vitro. Arthritis Rheum 1998, 41:263-273.

20. Walsh AJ, Bradford DS, Lotz JC: In vivo growth factor treatment of degenerated intervertebral discs. Spine 2004, 29:156-163.

21. Chujo T, An HS, Akeda K, Miyamoto K, Muehleman C, Attawia M, Andersson G, Masuda K: Effects of growth differentiation factor-5 on the intervertebral disc--in vitro bovine study and in vivo rabbit disc degeneration model study. Spine 2006, 31:2909-2917.

22. Cui M, Wan Y, Anderson DG, Shen FH, Leo BM, Laurencin CT, Balian G, Li X: Mouse growth and differentiation factor-5 pro- 
tein and DNA therapy potentiates intervertebral disc cell aggregation and chondrogenic gene expression. Spine J 2008, 8:287-295.

23. Sive JI, Baird P, Jeziorsk M, Watkins A, Hoyland JA, Freemont AJ: Expression of chondrocyte markers by cells of normal and degenerate intervertebral discs. Mol Pathol 2002, 55:91-97.

24. Wang JY, Baer AE, Kraus VB, Setton LA: Intervertebral disc cells exhibit differences in gene expression in alginate and monolayer culture. Spine 2001, 26:1747-1752.

25. Chiba K, Andersson GB, Masuda K, Thonar EJ: Metabolism of the extracellular matrix formed by intervertebral disc cells cultured in alginate. Spine 1997, 22:2885-2893.

26. Farndale RW, Buttle DJ, Barrett AJ: Improved quantitation and discrimination of sulphated glycosaminoglycans by use of dimethylmethylene blue. Biochim Biophys Acta 1986, 883:173-177.

27. Le Maitre CL, Freemont AJ, Hoyland JA: Accelerated cellular senescence in degenerate intervertebral discs: A possible role in the pathogenesis of intervertebral disc degeneration. Arthritis Res Ther 2007, 9:R45.

28. Freemont AJ, Peacock TE, Goupille P, Hoyland JA, O'Brien J, Jayson Ml: Nerve ingrowth into diseased intervertebral disc in chronic back pain. Lancet 1997, 350:178-181.

29. Freemont AJ, Watkins A, Le Maitre C, Baird P, Jeziorska M, Knight MT, Ross ER, O'Brien JP, Hoyland JA: Nerve growth factor expression and innervation of the painful intervertebral disc. $J$ Pathol 2002, 197:286-292.

30. Bai X, Xiao Z, Pan Y, Hu J, Pohl J, Wen J, Li L: Cartilage-derived morphogenetic protein-1 promotes the differentiation of mesenchymal stem cells into chondrocytes. Biochem Biophys Res Commun 2004, 325:453-460.

31. Li J, Kim KS, Park JS, Elmer WA, Hutton WC, Yoon ST: BMP-2 and CDMP-2: stimulation of chondrocyte production of proteoglycan. J Orthop Sci 2003, 8:829-835.

32. Le Maitre CL, Freemont AJ, Hoyland JA: The role of interleukin-1 in the pathogenesis of human intervertebral disc degeneration. Arthritis Res Ther 2005, 7:R732-R745.

33. Hauselmann HJ, Masuda K, Hunziker EB, Neidhart M, Mok SS, Michel BA, Thonar EJ: Adult human chondrocytes cultured in alginate form a matrix similar to native human articular cartilage. Am J Physiol 1996, 271:C742-C752.

34. Mok SS, Masuda K, Hauselmann HJ, Aydelotte MB, Thonar EJ: Aggrecan synthesized by mature bovine chondrocytes suspended in alginate. Identification of two distinct metabolic matrix pools. J Biol Chem 1994, 269:33021-33027.

35. Le Maitre CL, Pockert A, Buttle DJ, Freemont AJ, Hoyland JA: Matrix synthesis and degradation in human intervertebral disc degeneration. Biochem Soc Trans 2007, 35:652-655.

36. Zhao CQ, Jiang LS, Dai LY: Programmed cell death in intervertebral disc degeneration. Apoptosis 2006, 11:2079-2088.

37. Intradiscal rhGDF-5 Phase I/II Clinical Trial [http://clinicaltri als.gov/ct2/show/NCT00813813?term=GDF\&rank=1]

38. Le Maitre CL, Freemont AJ, Hoyland JA: A preliminary in vitro study into the use of IL-1Ra gene therapy for the inhibition of intervertebral disc degeneration. Int J Exp Pathol 2006, 87:17-28.

39. Le Maitre CL, Hoyland JA, Freemont AJ: Interleukin-1 receptor antagonist delivered directly and by gene therapy inhibits matrix degradation in the intact degenerate human intervertebral disc: an in situ zymographic and gene therapy study. Arthritis Res Ther 2007, 9:R83.

40. Kandel R, Roberts S, Urban JP: Tissue engineering and the intervertebral disc: the challenges. Eur Spine J 2008,17(Suppl 4):480-491. 